\title{
A narrative review on current duodenoscope reprocessing techniques and novel developments
}

\author{
Maarten Heuvelmans ${ }^{1 *} \mathbb{D}$, Herman F. Wunderink ${ }^{1}$, Henny C. van der Mei $^{2}$ and Jan F. Monkelbaan ${ }^{3}$
}

\begin{abstract}
Duodenoscopy-associated infections occur worldwide despite strict adherence to reprocessing standards. The exact scope of the problem remains unknown because a standardized sampling protocol and uniform sampling techniques are lacking. The currently available multi-society protocol for microbial culturing by the Centers for Disease Control and Prevention, the United States Food and Drug Administration (FDA) and the American Society for Microbiology, published in 2018 is too laborious for broad clinical implementation. A more practical sampling protocol would result in increased accessibility and widespread implementation. This will aid to reduce the prevalence of duodenoscope contamination. To reduce the risk of duodenoscopy-associated pathogen transmission the FDA advised four supplemental reprocessing measures. These measures include double high-level disinfection, microbiological culturing and quarantine, ethylene oxide gas sterilization and liquid chemical sterilization. When the supplemental measures were advised in 2015 data evaluating their efficacy were sparse. Over the past five years data regarding the supplemental measures have become available that place the efficacy of the supplemental measures into context. As expected the advised supplemental measures have resulted in increased costs and reprocessing time. Unfortunately, it has also become clear that the efficacy of the supplemental measures falls short and that duodenoscope contamination remains a problem. There is a lot of research into new reprocessing methods and technical applications trying to solve the problem of duodenoscope contamination. Several promising developments such as single-use duodenoscopes, electrolyzed acidic water, and vaporized hydrogen peroxide plasma are already applied in a clinical setting.
\end{abstract}

Keywords: Endoscopy, Reprocessing, Infection, Outbreak, Multidrug-resistant Enterobacterales

\section{Introduction}

Duodenoscopes are diagnostic and therapeutic instruments used to visualize the interior of the upper gastrointestinal tract, collect tissue samples and perform therapeutic interventions. Inherent to their use duodenoscopes carry the risk of acquiring microbial contamination [1]. Over the past decade duodenoscopy-associated outbreaks often caused by multidrug-resistant (MDR)

*Correspondence: M.Heuvelmans-12@umcutrecht.nl

${ }^{1}$ Department of Medical Microbiology, University Medical Center Utrecht, G04.643, PO box 85500, 3508GA Utrecht, The Netherlands

Full list of author information is available at the end of the article bacteria have been reported worldwide [2-15]. A report of the Emergency Care Research Institute in 2020 included sterile processing errors in medical and dental offices in the top ten of health technology hazards reflecting the increasing awareness and recognition of the risks of endoscopy-associated pathogen transmission in general [16]. Duodenoscopy-associated infections and outbreaks have also occurred despite strict adherence to reprocessing standards $[4,6,13,15]$.

The most common organisms involved in duodenoscopy-associated transmission are Klebsiella pneumoniae and Pseudomonas aeruginosa [2-15]. These bacterial pathogens are known for their biofilm 
formation and likelihood of multidrug resistance [11, $17,18]$. The predominance of MDR bacteria in duodenoscopy-associated outbreaks is most likely related to the fact that duodenoscopy-associated outbreaks are mainly noticed as a result of an elevated incidence of a specific MDR bacterium demanding infection control measures [2-15]. An elevated incidence of nonMDR bacteria is more likely to go unnoticed, leading to underestimation of duodenoscopy-associated pathogen transmission [8-10]. Duodenoscope contamination rates after reprocessing vary between 0.4 and $35.8 \%$. This high variability can be explained by the absence of standardized sampling and culture methods and different definitions used for duodenoscope contamination (Table 1) [19-30]. Duodenoscope contamination is defined as growth of a specific predefined set of oral and/or gastrointestinal bacteria or as growth above a predefined threshold of any type of microorganism regardless of origin. This is for example described in the professional standard of the Dutch steering group for flexible endoscope cleaning and disinfection and the guideline of the European Society of Gastrointestinal Endoscopy [31, 32]. Although such guidelines have clear definitions, in literature a wide array of definitions has been used (Table 1). This illustrates the lack of a uniform and clear definition, and a standardized protocol [19-30].

This narrative review aims to give an overview of the problems associated with duodenoscope reprocessing. Novel promising developments for reprocessing of duodenoscopes are summarized and discussed. The literature search for this narrative review used the search term "endoscop" which was combined with the different search terms regarding the topics discussed in this review on PubMed. Articles were first screened for eligibility based on title and abstract and all remaining full text articles were screened completely. A second search was performed on PubMed for all topics without the term "endoscop" to see if any articles were missed. Finally the selected articles were cross-referenced to reveal any additional missed articles.

Table 1 Culture positivity rate of duodenoscopes after strict adherence to reprocessing standards

\begin{tabular}{|c|c|c|c|c|}
\hline First definition of contamination & CPD (\%) & Second definition of contamination & CPD (\%) & References \\
\hline $\begin{array}{l}\text { Any growth of high-concern organisms }{ }^{a} \text { or }>10 \text { CFU of low- } \\
\text { concern organisms }{ }^{b}\end{array}$ & $18 \%$ & NA & NA & [29] \\
\hline Any growth of high-concern organisms ${ }^{c}$ & $4.9-5 \%$ & $>100$ CFU of low/moderate concern organisms ${ }^{d}$ & $0.6-4.4 \%$ & {$[21]$} \\
\hline Any growth of high-concern organisms ${ }^{e}$ & $0.4 \%$ & Growth of any organism & $7.7 \%$ & [30] \\
\hline Growth of any organism & $1.1 \%$ & NA & NA & [26] \\
\hline $\begin{array}{l}\text { Micro-organism of gastro-intestinal or oral origin regardless of } \\
\text { quantity }\end{array}$ & $15 \%$ & Growth of any organism $\geq 20 \mathrm{CFU} / \mathrm{ml}$ & $22 \%$ & [19] \\
\hline Any growth of Gram-negative bacillicDC & $4.2 \%$ & NA & NA & [25] \\
\hline $\begin{array}{l}\text { Growth } \geq 10 \mathrm{CFU} / \mathrm{ml} \text { on the elevator mechanism or working } \\
\text { channel }\end{array}$ & $2.3 \%$ & $\begin{array}{l}\text { Growth of any organism on the elevator mecha- } \\
\text { nism or working channel }\end{array}$ & $16.1 \%$ & [28] \\
\hline Any growth of pathogenic organisms ${ }^{g}$ & $0.9 \%$ & Growth of any organism & $8.4 \%$ & [23] \\
\hline$\geq 50 \mathrm{CFU} / \mathrm{ml}$ excluding skin contaminants ${ }^{\mathrm{h}}$ & $0.9 \%$ & Growth of any organism & $11 \%{ }^{i}$ & {$[20]$} \\
\hline Any growth of high-concern organisms ${ }^{C D C}$ & $2 \%$ & Growth of any organism $\mathrm{CDC}$ & $13.1 \%$ & [22] \\
\hline $\begin{array}{l}>100 \mathrm{CFU} \text { of total growth or any growth of high-concern } \\
\text { organisms }\end{array}$ & $35.8 \%$ & Growth of any organism above $\geq 25$ CFU & NA & {$[27]$} \\
\hline
\end{tabular}

Only studies published in the last decade have been included. Most studies report two definitions of contamination with accompanying contamination rates CPD culture positive duodenoscopes, percentage of duodenoscopes regarded contaminated according to the definition given; CFU/m/number of colony forming units per milliliter; NA not applicable; ${ }^{C D C}$ sampling was performed using the centers for disease control and prevention interim sampling protocol released in 2015

a Yeast, Staphylococcus aureus, Enterococcus species, Gram-negative enteric bacilli

${ }^{\mathrm{b}}$ coagulase-negative Staphylococcus species, Micrococcus species, Gram-positive rods

' Gram-negative rods, Staphylococcus aureus, beta-hemolytic Streptococcus, Enterococcus species, Yeast

d Undefined

${ }^{e}$ Escherichia coli, Enterococcus faecalis, Enterococcus faecium, Enterococcus species, Enterobacter cloacae, Aeromonas species

${ }^{f}$ Yeast, Klebsiella species, Escherichia species, Enterobacter species, Enterococcus species, Pseudomonas aeruginosa, Staphylococcus aureus, Moraxella species, Rothia species, Streptococcus species, and Neisseria species

${ }^{9}$ Enteric Gram-negative bacilli, Pseudomonas aeruginosa, Acinetobacter baumannii, Staphylococcus aureus, Enterococcus species and Stenotrophomonas maltophilia

${ }^{\mathrm{h}}$ Organisms not defined

i No number per endoscope provided, only a number of contaminated samples is available

j Staphylococcus aureus, Enterobacterales, Pseudomonas species, Stenotrophomonas maltophilia, Acinetobacter species and Candida species 


\section{Duodenoscope reprocessing}

The different guidelines used for duodenoscope reprocessing all use several comparable principal steps (Fig. 1) [33]. Variation within each step is common such as the chemical used for high-level disinfection (HLD) or the type of duodenoscope reprocessor. Immediately following the completion of the duodenoscopic procedure, reprocessing starts with a pre-cleaning step by wiping the outside of the duodenoscope with a cloth immersed in an enzymatic solution, flushing the channels with a detergent and removing all detachable parts of the duodenoscope [32-36]. After pre-cleaning the duodenoscope is transported to a cleaning facility where leak tests and manual cleaning are performed. Leak testing is performed to identify openings in the duodenoscope that can lead to entry of liquids, chemicals and organic debris [32-36]. Manual cleaning should be performed in accordance with manufacturer instructions and usually consists of submersion in a detergent solution, flushing and brushing of duodenoscope channels and cleaning of duodenoscope valves and the elevator mechanism. Directly afterwards the duodenoscope is thoroughly

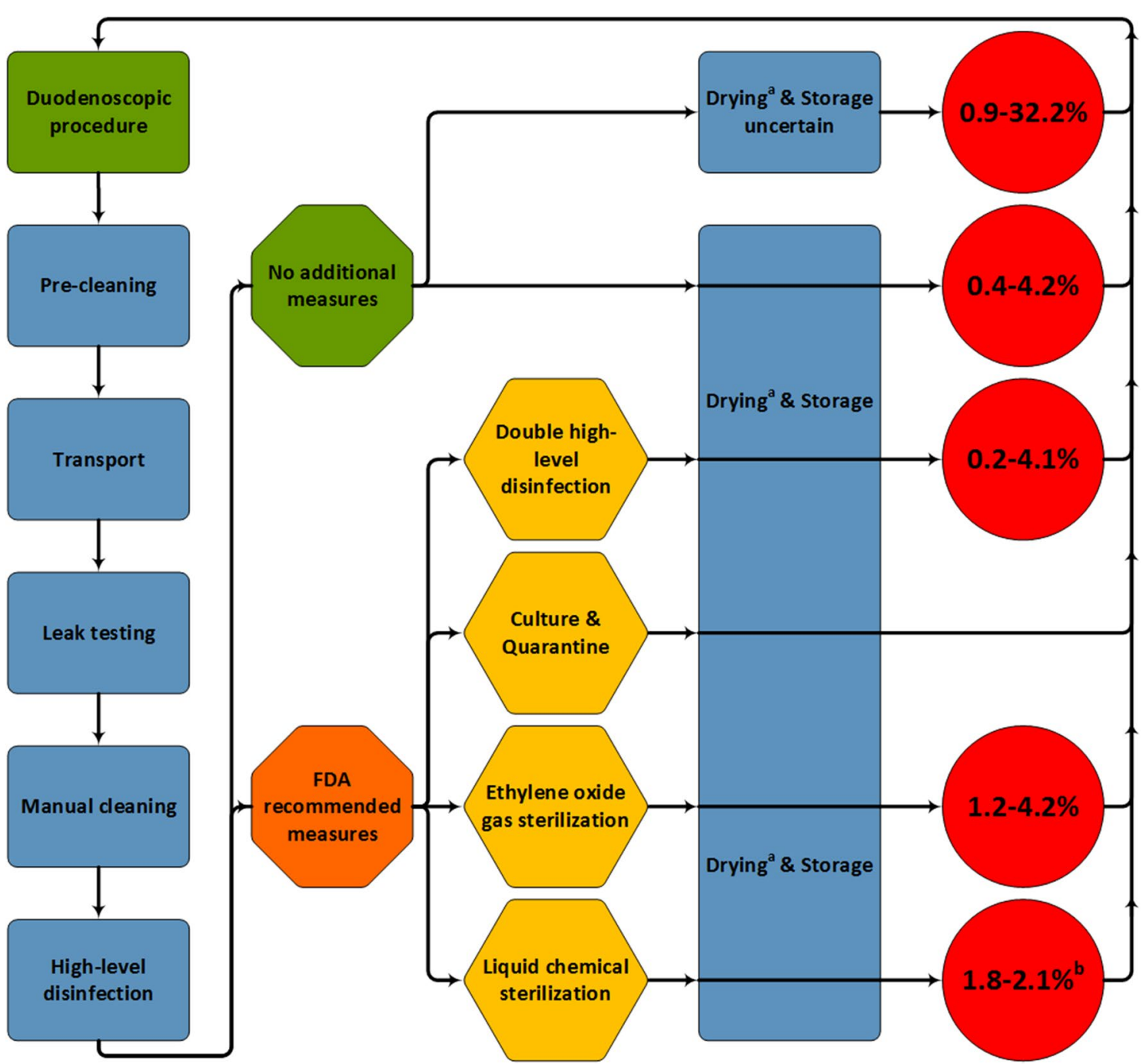

Fig. 1 Duodenoscope contamination rates after standard duodenoscope reprocessing and the supplemental reprocessing measures. The green rectangle represents the duodenoscopic procedure and the blue rectangles show the current standard of reprocessing [33]. The green octagon represents the standard reprocessing procedure and the orange octagon represents the addition of one of the supplemental reprocessing measures to the standard reprocessing procedure. After standard reprocessing, several studies describe drying and storage and others did not. The four supplemental measures which were advised by the FDA in 2015 are depicted in yellow hexagons [57]. Red circles indicate contamination rates $[19-30,59,80,93] .{ }^{a}$ Some guidelines allow limited drying-time $[38,42] .{ }^{b}$ One study used double HLD containing peracetic acid and hydrogen peroxide [29] 
rinsed with water to remove any residual detergent and debris that has been dislodged during the manual cleaning [32-36]. After manual cleaning HLD is performed which involves rinsing and flushing of the duodenoscope with a chemical such as glutaraldehyde that is capable of killing all micro-organisms on the outside and inside of the duodenoscope except for bacterial spores [1]. HLD can be performed manually or with an automated endoscope reprocessor. The last reprocessing step consists of drying and storage preferably in a cabinet facilitating drying by forced air flowing through the cabinet or through the duodenoscope channels [37]. It has been shown that when a duodenoscope is re-used within 3-4 $\mathrm{h}$ after HLD, only ten minutes of drying-time is sufficient to prevent bacterial growth [32, 34, 38-44]. When duodenoscopes are stored longer than 3-4 h continued drying is essential for duodenoscope reprocessing as even limited amounts of residual moisture may promote bacterial growth and biofilm formation [37, 42-45].

\section{Reprocessing failure}

The reprocessing procedure is essential because during use of duodenoscopes both the out- and inside are exposed to body fluids and potential contamination requiring disinfection before re-use of the duodenoscope [16]. This means that duodenoscopes go through a constant cycle of contamination and reprocessing. During these cycles organic material (extracellular matrix) and bacteria accumulate inside the duodenoscope channels also known as cyclic reprocessing build-up [46]. Deposition of organic material can further be facilitated by imperfections in the inner lining of the duodenoscope channels. These imperfections can already occur shortly after initial commissioning of the duodenoscope $[47,48]$. Accumulation of cyclic reprocessing build-up and subsequent seeding of this cyclic reprocessing build-up with bacteria will eventually lead to bacterial biofilm formation [39, 47-52]. Another important factor complicating the reprocessing of duodenoscopes is their complex design which contributes to reprocessing failure [10-14, 53]. Design issues have been linked to reprocessing failure and even outbreaks in the past $[10,11]$. The high duodenoscope contamination rate after reprocessing despite strict adherence to reprocessing protocols, strongly suggests that residual organic debris and bacterial biofilm formation occur (Table 1) [19-30, 52, 54-56].

The United States Food and Drug Administration (FDA) issued a statement in 2015 advising supplemental reprocessing measures for all duodenoscopes to minimize reprocessing failures. These supplemental reprocessing measures included double HLD, microbiological culturing and quarantine, ethylene oxide (EtO) gas sterilization or use of a liquid chemical sterilant [57]. By 2016,
89.6\% of surveyed healthcare facilities in the United States of America implemented at least one of these measures, with double HLD (63\%) and microbiological culturing and quarantine (53\%) used most frequently [58].

\section{Double high-level disinfection}

Double HLD consists of either a second cycle of HLD or repetition of the entire reprocessing procedure [28-30, 59]. This dual definition of double HLD and the fact that different studies use different HLD chemicals makes comparison between studies difficult [28-30, 59]. The additional time added to the entire reprocessing procedure by a second cycle of HLD is less than one hour and the additional costs are only $\$ 68.55$ resulting in the lowest added costs of all the supplemental measures [60].

To date both approaches of double HLD have shown no reduction of the contamination rate of duodenoscopes $[28,30,59]$. A reduction in contamination rate has been shown after several subsequent cycles of peracetic acid based HLD, the contamination rate decreased from $18 \%$ after the first cycle to below $1 \%$ after the third cycle [29]. Thus, although the increased reprocessing time and additional costs incurred by double HLD are limited, most data suggest that a second cycle of HLD is not effective.

\section{Microbiological culturing and quarantine}

Microbiological culturing and quarantine means that all duodenoscopes are sampled after reprocessing for microorganism detection. This entails that all duodenoscopes need to be quarantined until they are confirmed culture negative. When pathogens are identified from a reprocessed duodenoscope the duodenoscope needs to be reprocessed, cultured and quarantined again. Once cultures are definitively negative another reprocessing cycle should be performed before releasing the duodenoscope for clinical procedures. Persistently contaminated duodenoscopes should be evaluated by the manufacturer for internal damage and in case of MDR bacteria, patients exposed to the contaminated duodenoscope involved should be notified and considered for screening for their MDR bacterial carrier status [24].

Implementation of microbiological culturing and quarantine is costly and time consuming as it requires a microbiological infrastructure, trained personnel, enough duodenoscope storage capacity and a large number of duodenoscopes to continue duodenoscopic procedures while awaiting culturing results of reprocessed duodenoscopes that are quarantined [44, 60, 61]. However, in a non-outbreak setting periodical sampling of duodenoscopes is a more cost-effective option ensuring that all duodenoscopes are cultured over a preset period of time. Furthermore, in such a setting it will probably 
be worthwhile not to quarantine duodenoscopes while awaiting culture results [14, 24, 26, 62]. Of course when a duodenoscope is not quarantined pending culture results a positive microbiological culture will demand surveillance of patients exposed and outbreak control management.

There are different methods for duodenoscope sampling which vary in their sensitivity for detecting microbiological contamination (Table 2) [61, 63-68]. This variability of sensitivity possibly explains why outbreaks with a clear epidemiological link to a duodenoscope have revealed no contamination of the duodenoscope when cultures were taken $[5,6,14]$. Standardized methods for duodenoscope sampling and a uniform definition of duodenoscope contamination are lacking and current definitions are based on growth of specific pathogens, number of colony forming units or both (Table 1) [19-30]. This is the reason that reported duodenoscope contamination rates after reprocessing range from 0.4 to $35.8 \%$ (Table 1 ) [19-30].

The only multi-society protocol available for microbial culturing was released in 2018 by the Centers for Disease Control and Prevention (CDC), the FDA and the American Society for Microbiology (ASM) [61]. This protocol is divided in two sections describing the microbiological sampling and culturing methods. Microorganisms are classified as low- moderate- and high-concern and the protocol defines which actions are required in case of a positive microbiological culture. Gastrointestinal microorganisms such as Enterobacterales and Pseudomonas aeruginosa are always regarded as high-concern regardless of quantity. Microbiological flora such as coagulasenegative Staphylococcus species and Micrococcus species are defined as low/moderate-concern organisms and action is only required when the number of colony-forming units $(\mathrm{CFU} / \mathrm{ml})$ exceeds $100 \mathrm{CFU} / \mathrm{ml}$. Given that this protocol contains more than 100 steps and requires two persons for sampling makes it too laborious for use in clinical practice and general laboratories [61].

In conclusion, the high costs associated with a complete microbiological culturing and quarantine program preclude this measure as a definite solution for duodenoscope-associated transmission. However, microbiological culturing and quarantine protocols have shown to be useful in identifying failures in reprocessing procedures $[24,69,70]$.

\section{Ethylene oxide gas sterilization}

EtO has potent alkylating properties resulting in sterilization and has been used for at least 40 years [71-73]. EtO allows sterilization of instruments with thermolabile materials such as duodenoscopes due to the low temperature typically $50{ }^{\circ} \mathrm{C}$ at which the sterilization can be performed compared to the higher temperatures needed with other sterilization methods. In the past mixtures containing EtO with chlorofluorocarbon, hydrochlorofluorocarbons or carbon dioxide have been used. However, nowadays they are replaced by $100 \% \mathrm{EtO}$ gas due to environmental issues [74-76]. EtO is flammable and has carcinogenic properties and should therefore be handled with care [77].

In the presence of organic deposition and/or biofilm the efficacy of EtO is reduced due to limited penetration in organic materials and in a clinical setting no added benefit has been found from adding EtO gas sterilization after HLD $[28,75,78,79]$. Another disadvantage of EtO gas sterilization is that it is time-consuming. It takes approximately $13 \mathrm{~h}$, one hour exposure time with a 12-h aeration cycle due to absorption of EtO in the polymer materials of the duodenoscope creating a high burden on duodenoscope availability and decreasing cost-effectiveness $[60,80-82]$.

\section{Liquid chemical sterilization}

In contrast to an agent suited for HLD a sterilizing agent such as peracetic acid, sodium hypochlorite or hydrogen peroxide can also effectively kill bacterial spores [83, 84]. The strong oxidizing properties of these chemicals leads to sterilization of the device. Unfortunately, this strong oxidizing effect also results in corrosion of parts in the duodenoscopes which is why sodium hypochlorite and high concentrations of hydrogen peroxide are not used in clinical practice $[85,86]$.

Peracetic acid $(1820 \mathrm{mg} / \mathrm{l})$ is effective in sterilizing duodenoscopes of different manufacturers [87]. Effectivity has also been shown in colonoscopes contaminated with Enterococcus faecalis and in bronchoscopes contaminated with Mycobacterium gordonae [82, 88, 89]. Concerning organic deposition peracetic acid is superior to EtO gas because it removes organic deposition through flow [75]. The efficacy of peracetic acid against bacteria in biofilm is comparable to $O$-phatalaldehyde and is superior to glutaraldehyde [90]. It should however be noted that certain peracetic acid formulations can have a fixating effect on biofilm [91, 92]. In a clinical setting peracetic acid has been compared to double HLD revealing similar effectiveness [93]. Peracetic acid has also been used as HLD chemical but revealed contamination rates comparable to other HLD chemicals [29]. It should also be noted that peracetic acid is a highly toxic chemical and requires handling precautions $[94,95]$. Current data suggest that contamination of duodenoscopes still occurs after liquid chemical sterilization. Implementation of liquid chemical sterilization with peracetic acid requires limited modifications to the current reprocessing procedure because it only needs replacement of the chemical 


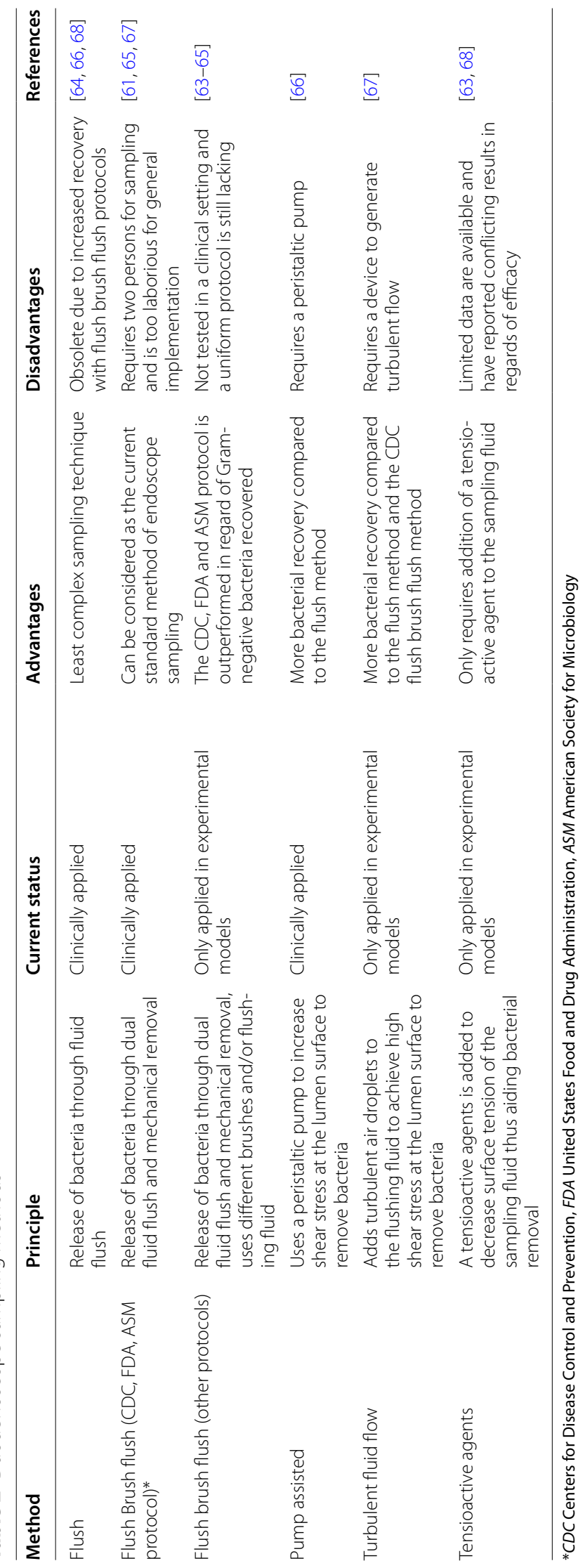


used in the HLD step. Therefore additional costs and added time will be limited compared to other interventions, such as EtO.

\section{Future perspectives}

Despite the disappointing results of the supplemental measures several promising innovations are under development such as, single-use duodenoscopes, bioburden assays, electrolyzed acidic water, vaporized hydrogen peroxide plasma, cavitation, methylene blue photodynamic therapy and plasma-activated gas (Table 3) [73, 79, 96-118]. Unfortunately, the lack of a uniform protocol and definition makes it difficult to simulate duodenoscope reprocessing in experimental models. Therefore, evaluation of the effects of these new methods and their usefulness compared to current reprocessing standards is difficult.

\section{Single-use duodenoscopes}

In 2019, the FDA approved the first single-use duodenoscopes [96]. Their use completely obviates the need for reprocessing but incurs significant higher costs compared to reusable duodenoscopes [97]. Cost-effectiveness will therefore depend on multiple factors such as rate of reusable duodenoscopy-associated infections, costs related to a possible duodenoscopy-associated infection or outbreak, the number of procedures performed annually and the performance of these single-use duodenoscopes compared to reusable duodenoscopes [97, 98]. Furthermore single-use duodenoscopes will without doubt lead to more waste and have an increased environmental impact.

\section{Bioburden assays}

Bioburden assays are rapid and low-cost tests which can detect the presence of organic soil by detecting biomarkers such as protein, hemoglobin or adenosine triphosphate (ATP) [99, 101]. Benchmarks regarding detection of protein or ATP have been described and used to evaluate the efficacy of manual cleaning [99101]. ATP has also been used to evaluate duodenoscope contamination but presence of ATP in organic material other than viable bacteria causes a poor correlation between ATP levels and bacterial contamination [101-103]. Furthermore, it should be noted that the sensitivity of bioburden assays will depend on the sampling method used. Given that a standardized method for collection of samples for testing with bioburden assays in duodenoscopes is currently unavailable precludes broad implementation.

\section{Electrolyzed acidic water}

To prepare electrolyzed acidic water an electric current is run through a saline solution resulting in acidity, hypochlorite ions and free chlorine which all contribute to bactericidal activity [104]. Efficacy has been shown in both a contaminated gastrointestinal endoscope model and clinical practice, and no bacteria were recovered when electrolyzed acidic water treatment was used for at least $5 \mathrm{~min}$ [104, 105]. The efficacy of electrolyzed acidic water depends on the amount of organic debris because of uptake of the bactericidal chemicals in the organic debris therefore adequate manual cleaning prior to use is warranted [106]. Interestingly, in a model utilizing metal cylinders without organic debris some cylinders still harbored viable bacteria after electrolyzed acidic water treatment [107]. Electrolyzed acidic water has been compared to glutaraldehyde and has comparable efficacy based on contamination rate [106, 108-110]. The advantages of electrolyzed acidic water are that it does not leave toxic residues, does not fixate proteins and thereby is less likely to promote biofilm [107]. A disadvantage of electrolyzed acidic water is that it needs to be used immediately after preparation because the efficacy of the

Table 3 New methods for duodenoscope reprocessing

\begin{tabular}{|c|c|c|c|c|}
\hline Method & Phase of development & Advantages & Disadvantages & References \\
\hline Single-use duodenoscope & Implemented & $\begin{array}{l}\text { No need for reprocessing, non- } \\
\text { toxic }\end{array}$ & $\begin{array}{l}\text { High costs, quality of duodeno- } \\
\text { scope }\end{array}$ & {$[96-98]$} \\
\hline Bioburden assays & Implemented & Quick and easy to use & $\begin{array}{l}\text { Lack of correlation with microbial } \\
\text { culture }\end{array}$ & {$[99-103]$} \\
\hline Electrolyzed acidic water & Endoscope tested & No biofilm fixation, non-toxic & Preparation on site needed & {$[104-110]$} \\
\hline $\begin{array}{l}\text { Vaporized hydrogen peroxide } \\
\text { plasma }\end{array}$ & Endoscope tested & No aeration needed, non-toxic & Material incompatibility & {$[73,79,111-115]$} \\
\hline Cavitation & Not tested & $\begin{array}{l}\text { Potentially effective against } \\
\text { biofilm, non-toxic }\end{array}$ & No disinfecting properties & {$[116]$} \\
\hline $\begin{array}{l}\text { Methylene blue photodynamic } \\
\text { therapy }\end{array}$ & Model tested & $\begin{array}{l}\text { Effective against biofilm, limited } \\
\text { toxicity }\end{array}$ & Practical application lacking & {$[117]$} \\
\hline Plasma-activated gas & Model tested & Non-toxic & Short-lived effect & [118] \\
\hline
\end{tabular}


solution decreases rapidly due to the unstable nature of the ions formed [106]. This complicates the reprocessing procedure because efficacy of HLD chemicals needs to be guaranteed through testing prior to use. Therefore if electrolyzed acid water is implemented this will increase reprocessing time because both preparation and testing of the solution need to be performed shortly before reprocessing of each duodenoscope. Electrolyzed acidic water has been cleared by the FDA since 2002 as a highlevel disinfectant.

\section{Vaporized hydrogen peroxide plasma}

In this method hydrogen peroxide vapor is used as primary sterilizer which in a second step is stimulated to form plasma and therewith antimicrobial free radicals such as hydroxyl and hydroperoxyl. The process results in low temperature sterilization without toxic byproducts and does not require an aeration cycle such as EtO $[73,111]$. Vaporized hydrogen peroxide plasma in laboratory studies has been shown to have potent sterilizing activity in long narrow lumens however when serum and salts are present efficacy is reduced with $65 \%$ due to hydrogen peroxide reacting with serum and salts [73, $79,111]$. No contamination was observed when experimentally contaminated flexible gastrointestinal endoscopes with Geobacillus stearothermophilus spores were examined for residual contamination after application of vaporized hydrogen peroxide plasma [111-114]. Vaporized hydrogen peroxide has also been used in conjunction with ozone as an additional sterilant which resulted in complete sterilization of duodenoscopes [115]. Vaporized hydrogen peroxide plasma sterilizers are a promising development for reprocessing, however data regarding clinical application are still limited. Furthermore there is still a matter of material incompatibility because the molybdenum disulphide lubricant used in duodenoscopes reacts with hydrogen peroxide creating corrosive acids that disintegrate the epoxy resin of the duodenoscope [114]. These material incompatibility issues will need to be solved before FDA approval or widespread implementation is considered.

\section{Cavitation}

Cavitation is a phenomenon in fluid dynamics where spherical cavities (microbubbles) are generated in a fluid through ultrasound [116]. Microbubbles interact with biofilm through a cycle of microbubble generation and collapse. Collapsing of these bubbles close to bacteria leads to bacterial damage and biofilm disintegration. Although cavitation could be a promising method for removal of biofilm during reprocessing it does not have disinfecting properties. Therefore cavitation can potentially be used prior to HLD for removal of biofilm and possibly increase the effectiveness of disinfection. Further research will be needed to determine if such strategies are feasible.

\section{Methylene blue photodynamic therapy}

This method uses laser light to induce reactive oxygen species in a methylene blue solution that exerts a bactericidal effect. The method can be enhanced by adding hydrogen peroxide which will also make it effective in the presence of biofilm [117]. Until now this method has only been used in an experimental model. The short half-life of reactive oxygen species makes it difficult to apply this method to duodenoscopes.

\section{Plasma-activated gas}

This method uses an electrical current to induce a plasma state in argon gas. This plasma-activated gas is directed through the duodenoscope channel to induce bactericidal reactive oxygen and nitrogen species [118]. Given that plasma-activated gas only produces short-lived (microseconds) reactive oxygen and nitrogen species, its toxicity is limited and therefore does not require an aeration cycle like EtO [118]. Currently this technique has only been applied in a polytetrafluoroethylene test tube model and therefore further research will be necessary to evaluate if plasma-activated gas is also effective and practical in a clinical setting.

\section{Discussion}

Duodenoscopy-associated infections and outbreaks occur worldwide but the exact scope of the problem is unknown [2-15]. Reported outbreaks almost exclusively involve MDR bacteria making it likely that outbreaks with other (non-MDR) microorganisms remain undetected [2-15]. Monitoring and estimation of duodenoscopyassociated transmission can be achieved by determining the contamination rate. The only available guideline for sampling and culturing of duodenoscopes is a multisociety guideline of the CDC, the FDA and the ASM [61]. Unfortunately, this guideline contains over 100 steps making it too laborious for widespread implementation in general laboratories [61]. Therefore development of a uniform and foremost more practical sampling protocol for duodenoscope contamination is of the utmost importance because this would results in more widespread implementation. New sampling methods for microbiological culturing can play a major role in such a protocol in the future (Table 2) [63-67, 70]. If such a uniform and more practical sampling protocol for duodenoscope contamination is developed this will facilitate data collection. When more data regarding duodenoscope contamination become available this will lead, to not only a more precise estimation of the duodenoscope contamination rate, 
but will also facilitate collection in a central database and lead to opportunities to examine new reprocessing techniques and procedures.

The implementation of the FDA proposed supplemental reprocessing measures to improve duodenoscope reprocessing outcomes has not resulted in reduction of the duodenoscope contamination rate (Fig. 1) [19-30, 57, $59,80,93]$. Implementation of the supplemental measures has however increased reprocessing time and costs. Therefore continued use of the supplemental measures to reduce the duodenoscope contamination rate is not sensible.

Perhaps the solution to the problem of ongoing bacterial contamination of duodenoscopes after reprocessing can be found in novel technical applications and reprocessing techniques. Newly proposed methods for improvement of duodenoscope reprocessing are promising and some have already been applied in the reprocessing procedure of duodenoscopes (Table 3) [73, 79, 96-118]. Several other promising methods however still remain in a very preliminary phase of development and will benefit from a practical standardized sampling protocol so their effect on the duodenoscope contamination rate can more easily and rapidly be determined (Table 3) [116-118]. This would surely aid in determining their usefulness in the reprocessing procedure and allow comparison to current reprocessing techniques and procedures.

Single-use duodenoscopes would surpass the current problems of reprocessing. However, these singleuse duodenoscopes are expensive, increase waste and cost-effectiveness will depend on performance, rate of infection, costs incurred per infection and number of procedures performed annually [96-98]. Bioburden assays can contribute to monitoring of manual cleaning however they are unsuited to replace microbiological culturing [99-103]. Furthermore lack of a uniform and standardized protocol for sampling of duodenoscopes precludes implementation of bioburden assays.

Implementation of novel reprocessing methods that will replace parts of or add-on to the existing reprocessing methods such as electrolyzed acidic water, vaporized hydrogen peroxide plasma, cavitation methylene blue photodynamic therapy or plasma-activated gas suffer from lack of a uniform and practical sampling protocol. Lack of such a duodenoscope sampling protocol makes comparison to current reprocessing methods and techniques difficult.

\section{Conclusions}

Reported duodenoscope contamination rates show that the current reprocessing methods are inadequate and underline the need for further research into novel reprocessing methods to improve reprocessing results so that duodenoscopy-associated infections and outbreaks can be prevented in the future. Development of a uniform and practical protocol for duodenoscope sampling that can be applied in general healthcare facilities is urgently needed and will facilitate development of novel reprocessing techniques because comparison between current and novel reprocessing methods can be more readily made.

\section{Abbreviations \\ MDR: Multidrug-resistant; HLD: High-level disinfection; FDA: United States Food and Drug Administration; EtO: Ethylene oxide; CDC: Centers for Disease Control and Prevention; ASM: American Society for Microbiology; CFU/ml: Colony-forming units per milliliter; ATP: Adenosine triphosphate; CPD: Culture positive duodenoscopes; NA: Not applicable.}

Acknowledgements

Not applicable.

Authors' contributions

MH has drafted the main body of the manuscript. HFW, HCvdM and JFM have contributed to writing and critical revision of the manuscript. All authors read and approved the final manuscript.

\section{Funding}

Not applicable.

Availability of data and materials

Not applicable.

\section{Declarations}

Ethics approval and consent to participate Not applicable.

Consent for publication

Not applicable.

Competing interests

The authors declare that they have no conflict of interest.

\section{Author details}

${ }^{1}$ Department of Medical Microbiology, University Medical Center Utrecht, G04.643, PO box 85500, 3508GA Utrecht, The Netherlands. ${ }^{2}$ Department of Biomedical Engineering, University of Groningen and University Medical Center Groningen, Groningen, The Netherlands. ${ }^{3}$ Department of Gastroenterology and Hepatology, University Medical Center Utrecht, Utrecht, The Netherlands.

Received: 15 July 2021 Accepted: 19 November 2021

Published online: 23 December 2021

\footnotetext{
References

1. Benowitz I, Moulton-Meissner HA, Epstein L, et al. The centers for disease control and prevention guidance on flexible gastrointestinal endoscopes: lessons learned from outbreaks, infection control. Gastrointest Endosc Clin N Am. 2020;30:723-33.

2. Yang $\mathrm{S}$, Hemarajata P, Hindler J, et al. Evolution and transmission of carbapenem-resistant Klebsiella pneumoniae expressing the bla OXA-232 gene during an institutional outbreak associated with endoscopic retrograde cholangiopancreatography. Clin Infect Dis. 2017;64:894-901.

3. Naas T, Cuzon G, Babics A, et al. Endoscopy-associated transmission of carbapenem-resistant Klebsiella pneumoniae producing KPC-2 betalactamase. J Antimicrob Chemother. 2010;65:1305-6.
} 
4. Rubin ZA, Kim S, Thaker AM, et al. Safely reprocessing duodenoscopes: current evidence and future directions. Lancet Gastroenterol Hepatol. 2018;3:499-508.

5. Gastmeier P, Vonberg RP. Klebsiella spp. in endoscopy-associated infections: we may only be seeing the tip of the iceberg. Infection. 2014;42:15-21.

6. Shenoy ES, Pierce VM, Walters MS, et al. Transmission of mobile colistin resistance ( $m$ cr-1) by duodenoscope. Clin Infect Dis. 2019;68:1327-34.

7. Bajolet $\mathrm{O}$, Ciocan D, Vallet C, et al. Gastroscopy-associated transmission of extended-spectrum beta-lactamase-producing Pseudomonas aeruginosa. J Hosp Infect. 2013;83:341-3.

8. Smith ZL, Oh YS, Saeian K, et al. Transmission of carbapenem-resistant Enterobacteriaceae during ERCP: time to revisit the current reprocessing guidelines. Gastrointest Endosc. 2015;81:1041-5.

9. Epstein L, Hunter JC, Arwady MA, et al. New Delhi metallo- $\beta$-lactamaseproducing carbapenem-resistant Escherichia coli associated with exposure to duodenoscopes. J Am Med Assoc. 2014;312:1447-55.

10. Rauwers AW, Troelstra A, Fluit AC, et al. Independent root cause analysis of contributing factors, including dismantling of 2 duodenoscopes, to an outbreak of multidrug-resistant Klebsiella pneumoniae. Gastrointest Endosc. 2019;90:793-804.

11. Verfaillie CJ, Bruno MJ, voor in't Holt AF, et al. Withdrawal of a noveldesign duodenoscope ends outbreak of a VIM-2-producing Pseudomonas aeruginosa. Endoscopy. 2015;47:493-502.

12. Bourigault C, Le Gallou F, Bodet N, et al. Duodenoscopy: an amplifier of cross-transmission during a carbapenemase-producing Enterobacteriaceae outbreak in a gastroenterology pathway. J Hosp Infect. 2018;99:422-6.

13. Kovaleva J, Meessen NEL, Peters FTM, et al. Is bacteriologic surveillance in endoscope reprocessing stringent enough? Endoscopy. 2009:41:913-6.

14. Fraser TG, Reiner S, Malczynski M, et al. Multidrug-resistant Pseudomonas aeruginosa cholangitis after endoscopic retrograde cholangiopancreatography: failure of routine endoscope cultures to prevent an outbreak. Infect Control Hosp Epidemiol. 2004;25:856-9.

15. Potron A, Bernabeu S, Cuzon G, et al. Analysis of OXA-204 carbapenemase-producing Enterobacteriaceae reveals possible endoscopy associated transmission, France, 2012 to 2014. Eurosurveillance. 2017;22:1-8.

16. The Lancet Gastroenterology \& Hepatology. Scoping the problem: endoscopy-associated infections. Lancet Gastroenterol Hepatol. 2018:3:445.

17. Piperaki ET, Syrogiannopoulos GA, Tzouvelekis LS, et al. Klebsiella pneumoniae: virulence, biofilm and antimicrobial resistance. Pediatric Infect Dis J. 2017;36:1002-5.

18. Maurice NM, Bedi B, Sadikot RT. Pseudomonas aeruginosa biofilms: Host response and clinical implications in lung infections. Am J Respir Cell Mol Biol. 2018;58:428-39.

19. Rauwers AW, Voor In't Holt AF, Buijs JG, et al. High prevalence rate of digestive tract bacteria in duodenoscopes: a nationwide study. Gut. 2018:67:1637-45

20. Paula H, Presterl E, Tribl B, et al. Microbiologic surveillance of duodenoscope reprocessing at the Vienna university hospital from november 2004 through March 2015. Infect Control Hosp Epidemiol. 2015:36:1233-5.

21. U. S. Food and Drug Administration. 522 Postmarket Surveillance Studies Database. 2019.

22. Ross AS, Baliga C, Verma P, et al. A quarantine process for the resolution of duodenoscope-associated transmission of multidrug-resistant Escherichia coli. Gastrointest Endosc. 2015:82:477-83.

23. Brandabur JJ, Leggett JE, Wang L, et al. Surveillance of guideline practices for duodenoscope and linear echoendoscope reprocessing in a large healthcare system. Gastrointest Endosc. 2016;84:392-9.e3.

24. Higa JT, Choe J, Tombs D, et al. Optimizing duodenoscope reprocessing: rigorous assessment of a culture and quarantine protocol. Gastrointest Endosc. 2018:88:223-9.

25. Chapman CG, Siddiqui UD, Manzano M, et al. Risk of infection transmission in curvilinear array echoendoscopes: results of a prospective reprocessing and culture registry. Gastrointest Endosc. 2017;85:390-7. e1.
26. Ma GK, Pegues DA, Kochman ML, et al. Implementation of a systematic culturing program to monitor the efficacy of endoscope reprocessing: outcomes and costs. Gastrointest Endosc. 2018:87:104-9.e3.

27. Saliou P, Garlantézec R, Baron R, et al. Contrǒles microbiologiques des endoscopes au centre hospitalier régional de Brest du 1er janvier 2007 au 31 décembre 2009 [Microbiological investigation of endoscopes at Brest Hospital over a period from 2007 to 2009]. Pathol Biol (Paris). 2011;59:88-93.

28. Snyder GM, Wright SB, Smithey A, et al. Randomized comparison of 3 high-level disinfection and sterilization procedures for duodenoscopes. Gastroenterology. 2017;153:1018-25.

29. Mark JA, Underberg K, Kramer RE. Results of duodenoscope culture and quarantine after manufacturer-recommended cleaning process. Gastrointest Endosc. 2020;91:1328-33.

30. Bartles RL, Leggett JE, Hove S, et al. A randomized trial of single versus double high-level disinfection of duodenoscopes and linear echoendoscopes using standard automated reprocessing. Gastrointest Endosc. 2018:88:306-13.e2.

31. Beilenhoff U, Neumann CS, Rey JF, et al. European Society of Gastrointestinal Endoscopy (ESGE) - European Society of Gastroenterology Nurses and Associates (ESGENA) guideline for quality assurance in reprocessing: Microbiological surveillance testing in endoscopy. Endoscopy. 2007;39:175-81.

32. Steering Group for Flexible Endoscope Cleaning and Disinfection. Kwaliteitshandboek reiniging en desinfectie flexibele endoscopen [Professional standard handbook cleaning and disinfection flexible endoscopes]. 2019.

33. Kim S, Muthusamy VR. Current practice of duodenoscope reprocessing Curr Gastroenterol Rep. 2016;18:1-8.

34. Beilenhoff $U$, Biering $H$, Blum R, et al. Reprocessing of flexible endoscopes and endoscopic accessories used in gastrointestinal endoscopy: position Statement of the European Society of Gastrointestinal Endoscopy (ESGE) and European society of gastroenterology nurses and associates (ESGENA). Endoscopy. 2018;50:1205-34.

35. Petersen BT, Cohen J, Hambrick RD, et al. Multisociety guideline on reprocessing flexible Gl endoscopes: 2016 update. Gastrointest Endosc. 2017:85:282-94.e1.

36. Marya NB, Muthusamy RV. Methods for endoscope reprocessing. Gastrointest Endosc Clin N Am. 2020;30:665-75.

37. Perumpail RB, Marya NB, McGinty BL, et al. Endoscope reprocessing: Comparison of drying effectiveness and microbial levels with an automated drying and storage cabinet with forced filtered air and a standard storage cabinet. Am J Infect Control. 2019;47:1083-9.

38. Kovaleva J. Endoscope drying and its pitfalls. J Hosp Infect. 2017;97:319-28.

39. Ofstead CL, Heymann OL, Quick MR, et al. Residual moisture and waterborne pathogens inside flexible endoscopes: evidence from a multisite study of endoscope drying effectiveness. Am J Infect Control. 2018:46:689-96.

40. Alfa MJ, Singh H. Impact of wet storage and other factors on biofilm formation and contamination of patient-ready endoscopes: a narrative review. Gastrointest Endosc. 2020;91:236-47.

41. Ofstead $\mathrm{CL}$, Wetzler $\mathrm{HP}$, Heymann $\mathrm{OL}$, et al. Longitudinal assessment of reprocessing effectiveness for colonoscopes and gastroscopes: results of visual inspections, biochemical markers, and microbial cultures. Am J Infect Control. 2017:45:e26-33.

42. Kovaleva J, Degener JE, van der Mei HC. Mimicking disinfection and drying of biofilms in contaminated endoscopes. J Hosp Infect. 2010;76:345-50.

43. Pineau L, Villard E, Duc DL, et al. Endoscope drying/storage cabinet: interest and efficacy. J Hosp Infect. 2008;68:59-65.

44. Barakat MT, Banerjee S. Novel algorithms for reprocessing, drying and storing endoscopes. Gastrointest Endosc Clin N Am. 2020;30:677-91.

45. Brock AS, Steed LL, Freeman J, et al. Endoscope storage time: Assessment of microbial colonization up to 21 days after reprocessing. Gastrointest Endosc. 2015;81:1150-4.

46. Zhong W, Alfa M, Zelenitsky S, et al. Simulation of cyclic reprocessing buildup on reused medical devices. Comput Biol Med. 2009:39:568-77.

47. Thaker AM, Kim S, Sedarat A, et al. Inspection of endoscope instrument channels after reprocessing using a prototype borescope. Gastrointest Endosc. 2018:88:612-9. 
48. Barakat MT, Girotra M, Huang RJ, et al. Scoping the scope: endoscopic evaluation of endoscope working channels with a new highresolution inspection endoscope (with video). Gastrointest Endosc 2018;88:601-11.

49. Pajkos A, Vickery K, Cossart Y. Is biofilm accumulation on endoscope tubing a contributor to the failure of cleaning and decontamination? J Hosp Infect. 2004;58:224-9.

50. Ofstead CL, Wetzler HP, Eiland JE, et al. Assessing residual contamination and damage inside flexible endoscopes over time. Am J Infect Control. 2016:44:1675-7.

51. Balan GG, Rosca I, Ursu E-L, et al. Duodenoscope-associated infections beyond the elevator channel: Alternative causes for difficult reprocessing. Molecules. 2019;24:1-13.

52. Hervé RC, Keevil CW. Persistent residual contamination in endoscope channels. A fluorescence epimicroscopy study Endoscopy. 2016:48:609-16.

53. Alfa MJ, Singh H, Duerksen DR, et al. Improper positioning of the elevator lever of duodenoscopes may lead to sequestered bacteria that survive disinfection by automated endoscope reprocessors. Am J Infect Control. 2018:46:73-5

54. Vickery K, Pajkos A, Cossart Y. Removal of biofilm from endoscopes: evaluation of detergent efficiency. Am J Infect Control. 2004;32:170-6.

55. Hervé R, Keevil CW. Current limitations about the cleaning of luminal endoscopes. J Hosp Infect. 2013:83:22-9.

56. Zühlsdorf $B$, Emmrich $M$, Floss $H$, et al. Cleaning efficacy of nine different cleaners in a washer-disinfector designed for flexible endoscopes. J Hosp Infect. 2002;52:206-11.

57. U. S. Food and Drug Administration. Supplemental measures to enhance duodenoscope reprocessing: FDA safety communication. Safety Commun 2015

58. Thaker AM, Muthusamy VR, Sedarat A, et al. Duodenoscope reprocessing practice patterns in US endoscopy centers: a survey study. Gastrointest Endosc. 2018;88:316-22.e2.

59. Rex DK, Sieber M, Lehman GA, et al. A double-reprocessing high-level disinfection protocol does not eliminate positive cultures from the elevators of duodenoscopes. Endoscopy. 2018;50:588-96.

60. Almario CV, May FP, Shaheen NJ, et al. Cost utility of competing strategies to prevent endoscopic transmission of carbapenem-resistant Enterobacteriaceae. Am J Gastroenterol. 2015;110:1666-74.

61. U. S. Food Drug Administration, Centers for Disease Control and Prevention, American Society for Microbiology. Duodenoscope surveillance. Sampl Cult. 2018:1-28.

62. Gillespie EE, Kotsanas D, Stuart RL. Microbiological monitoring of endoscopes: 5-year review. J Gastroenterol Hepatol (Aust). 2008;23:1069-74.

63. Alfa MJ, Singh $H$, Nugent $Z$, et al. Sterile reverse osmosis water combined with friction are optimal for channel and lever cavity sample collection of flexible duodenoscopes. Front Med. 2017:4:191.

64. Cattoir $L$, Vanzieleghem T, Florin L, et al. Surveillance of endoscopes: comparison of different sampling techniques. Infect Control Hosp Epidemiol. 2017;38:1062-9.

65. Gazdik MA, Coombs J, Burke JP, et al. Comparison of two culture methods for use in assessing microbial contamination of duodenoscopes. J Clin Microbiol. 2016;54:312-6.

66. Ji XY, Ning PY, Zhang W, et al. Microbiologic assessment of flexible gastrointestinal endoscope reprocessing using a pump-assisted sampling technique: an investigation involving all endoscopy units in Tianjin. China Am J Infect Control. 2018:46:e43-8.

67. Sohn SY, Alfa MJ, Lai R, et al. Turbulent fluid flow is a novel closedsystem sample extraction method for flexible endoscope channels of various inner diameters. J Microbiol Methods. 2020;168:105782.

68. Aumeran C, Thibert E, Chapelle FA, et al. Assessment on experimental bacterial biofilms and in clinical practice of the efficacy of sampling solutions for microbiological testing of endoscopes. J Clin Microbiol. 2012;50:938-42.

69. Chiu K-W, Fong T-V, Wu K-L, et al. Surveillance culture of endoscope to monitor the quality of high-level disinfection of gastrointestinal reprocessing. Hepatogastroenterology. 2010;57:531-4.

70. Moses FM, Lee J. Surveillance cultures to monitor quality of gastrointestinal endoscope reprocessing. Am J Gastroenterol. 2003;98:77-81.

71. Chmel H, Armstrong D. Salmonella oslo. A focal outbreak in a hospital. Am J Med. 1976:60:203-8.
72. Foliente RL, Kovacs BJ, Aprecio RM, et al. Efficacy of high-level disinfectants for reprocessing Gl endoscopes in simulated-use testing. Gastrointest Endosc. 2001:53:456-62.

73. Rutala WA, Gergen MF, Weber DJ. Comparative evaluation of the sporicidal activity of new low-temperature sterilization technologies: Ethylene oxide, 2 plasma sterilization systems, and liquid peracetic acid. Am J Infect Control. 1998;26:393-8.

74. Rutala WA, Weber DJ, Healthcare Infection Control Practices Advisory C. Guideline for disinfection and sterilization in healthcare facilities, 2008. CDC website. 2019

75. Alfa MJ, DeGagne P, Olson N, et al. Comparison of liquid chemical sterilization with peracetic acid and ethylene oxide sterilization for long narrow lumens. Am J Infect Control. 1998;26:469-77.

76. Ujeyl AK, Wurbs D, Adam W, et al. Gas sterilization of fiber endoscopes. Endoscopy. 1978;10:71-4.

77. Rutala WA, Weber DJ. ERCP Scopes: What can we do to prevent infections? Infect Control Hosp Epidemiol. 2015;36:643-8.

78. Epstein AK, Pokroy B, Seminara A, et al. Bacterial biofilm shows persistent resistance to liquid wetting and gas penetration. Proc Natl Acad Sci USA. 2011:108:995-1000.

79. Alfa MJ, DeGagne P, Olson N, et al. Comparison of ion plasma, vaporized hydrogen peroxide, and $100 \%$ ethylene oxide sterilizers to the 12/88 ethylene oxide gas sterilizer. Infect Control Hosp Epidemiol. 1996:17:92-100.

80. Naryzhny I, Silas D, Chi K. Impact of ethylene oxide gas sterilization of duodenoscopes after a carbapenem-resistant Enterobacteriaceae outbreak. Gastrointest Endosc. 2016;84:259-62.

81. Smith ZL, Dua A, Saeian K, et al. A novel protocol obviates endoscope sampling for carbapenem-resistant Enterobacteriaceae: Experience of a center with a prior outbreak. Dig Dis Sci. 2017;62:3100-9.

82. Wallace CG, Agee PM, Demicco DD. Liquid chemical sterilization using peracetic acid: an alternative approach to endoscope processing. ASAIO J. 1995:41:151-4

83. Rutala WA. Association of Practitioners in Infection Control (APIC) guideline for selection and use of disinfectants. Am J Infect Control. 1990;18:99-117.

84. Environmental Protection A. List A: EPA's registered antimicrobial products as sterilizers. 2016.

85. Coates D, Death JE. Use of buffered hypochlorite solution for disinfecting fibrescopes. J Clin Pathol. 1982;35:296-303.

86. Olympus America I. Sporox compatibility. 2009

87. McDonnell G, Ehrman M, Kiess S. Effectiveness of the SYSTEM $1 E$ liquid chemical sterilant processing system for reprocessing duodenoscopes. Am J Infect Control. 2016;44:685-8.

88. Cronmiller JR, Nelson DK, Salman G, et al. Antimicrobial efficacy of endoscopic disinfection procedures: a controlled, multifactorial investigation. Gastrointest Endosc 1997;45

89. Kim J-B, Han D-S, Kim J-P, et al. The value of peracetic acid (Scotelin ${ }^{\circledR}$ ) for endoscopic disinfection. Gastrointest Endosc. 2004;59:119.

90. Neves MS, Da Silva MG, Ventura GM, et al. Effectiveness of current disinfection procedures against biofilm on contaminated $\mathrm{Gl}$ endoscopes. Gastrointest Endosc. 2016;83:944-53.

91. Henoun Loukili $\mathrm{N}$, Becker $\mathrm{H}_{1}$ Harno J, et al. Effect of peracetic acid and aldehyde disinfectants on biofilm. J Hosp Infect. 2004;58:151-4.

92. Henoun Loukili N, Granbastien B, Faure K, et al. Effect of different stabilized preparations of peracetic acid on biofilm. J Hosp Infect. 2006;63:70-2.

93. Gromski MA, Sieber MS, Sherman S, et al. Double high-level disinfection versus liquid chemical sterilization for reprocessing of duodenoscopes used for ERCP: a prospective randomized study. Gastrointest Endosc 2020:1-5

94. Committee on Acute Exposure Guideline Levels, Committee on Toxicology, Board on Environmental Studies and Toxicology. Acute exposure guideline levels for selected airborne chemicals. 2010.

95. Walters Gl, Burge PS, Moore VC, et al. Occupational asthma caused by peracetic acid-hydrogen peroxide mixture. Occup Med. 2019;69:294-7.

96. Pluchino K, Caccomo S. FDA clears first fully disposable duodenoscope, eliminating the potential for infections caused by ineffective reprocessing.

97. Bang JY, Sutton B, Hawes R, et al. Concept of disposable duodenoscope: At what cost? Gut. 2019:68:1915-7. 
98. Chua T, Halim N, Reicher S. Recent advances in endoscope disinfection: Where do we stand in the COVID era? Tech Innov Gastrointest Endosc. 2021;23:190-8.

99. Alfa MJ, Olson N, Murray BL. Comparison of clinically relevant benchmarks and channel sampling methods used to assess manual cleaning compliance for flexible gastrointestinal endoscopes. Am J Infect Control. 2014;42:e1-e.

100. Alfa MJ, Fatima I, Olson N. The adenosine triphosphate test is a rapid and reliable audit tool to assess manual cleaning adequacy of flexible endoscope channels. Am J Infect Control. 2013;41:249-53.

101. Visrodia K, Hanada Y, Pennington KM, et al. Duodenoscope reprocessing surveillance with adenosine triphosphate testing and terminal cultures: a clinical pilot study. Gastrointest Endosc. 2017;86:180-6.

102. Visrodia $\mathrm{KH}$, Ofstead $\mathrm{CL}$, Yellin $\mathrm{HL}$, et al. The use of rapid indicators for the detection of organic residues on clinically used gastrointestinal endoscopes with and without visually apparent debris. Infect Control Hosp Epidemiol. 2014;35:987-94.

103. Hansen D, Benner D, Hilgenhöner M, et al. ATP measurement as method to monitor the quality of reprocessing flexible endoscopes. German Med Sci GMS e-J. 2004;2.

104. Tsuji S, Kawano S, Oshita M, et al. Endoscope disinfection using acidic electrolytic water. Endoscopy. 1999:31:528-35.

105. Urata M, Isomoto H, Murase K, et al. Comparison of the microbicidal activities of superoxidised and ozonated water in the disinfection of endoscopes. J Int Med Res. 2003;31:299-306.

106. Selkon JB, Babb JR, Morris R. Evaluation of the antimicrobial activity of a new super-oxidized water, Sterilox ${ }^{\circledR}$, for the disinfection of endoscopes. J Hosp Infect. 1999;41:59-70.

107. Nakano Y, Akamatsu N, Mori T, et al. Sequential washing with electrolyzed alkaline and acidic water effectively removes pathogens from metal surfaces. PLoS ONE. 2016:11:e0156058

108. Jun HL, Rhee PL, Jeong HK, et al. Efficacy of electrolyzed acid water in reprocessing patient-used flexible upper endoscopes: Comparison with $2 \%$ alkaline glutaraldehyde. J Gastroenterol Hepatol (Aust). 2004:19:897-903.

109. Pereira-Filho D, Alves PRA, Rossi F, et al. Disinfection of colonoscopes by using electrolyzed acid water: Is it effective? Gastrointest Endosc. 2005:61:120.

110. Sakurai Y, Ogoshi K, Okubo T, et al. Strongly acidic electrolyzed water: Valuable disinfectant of endoscopes. Dig Endosc. 2002;14:61-6.

111. Kyi MS, Holton J, Ridgway GL. Assessment of the efficacy of a low temperature hydrogen peroxide gas plasma sterilization system. J Hosp Infect. 1995;31:275-84.

112. Okpara-Hofmann J, Knoll M, Dürr M, et al. Comparison of low-temperature hydrogen peroxide gas plasma sterilization for endoscopes using various Sterrad ${ }^{\mathrm{TM}}$ models. J Hosp Infect. 2005;59:280-5.

113. Shintani H. Application of vapor phase hydrogen peroxide sterilization to endoscope. Biocontrol Sci. 2009;14:39-45.

114. Omidbakhsh N, Manohar S, Vu R, et al. Flexible gastrointestinal endoscope processing challenges, current issues and future perspectives. J Hosp Infect. 2021;110:133-8.

115. Molloy-Simard V, Lemyre JL, Martel K, et al. Elevating the standard of endoscope processing: Terminal sterilization of duodenoscopes using a hydrogen peroxide-ozone sterilizer. Am J Infect Control. 2019:47:243-50

116. Vyas N, Manmi K, Wang Q, et al. Which parameters affect biofilm removal with acoustic cavitation? A Review Ultrasound. Med Biol. 2019;45:1044-55.

117. Yang SM, Lee DW, Park HJ, et al. Hydrogen peroxide enhances the antibacterial effect of methylene blue-based photodynamic therapy on biofilm-forming bacteria. Photochem Photobiol. 2019;95:833-8.

118. Bhatt S, Mehta P, Chen C, et al. Efficacy of low-temperature plasma-activated gas disinfection against biofilm on contaminated Gl endoscope channels. Gastrointest Endosc. 2019:89:105-14.

\section{Publisher's Note}

Springer Nature remains neutral with regard to jurisdictional claims in published maps and institutional affiliations.

Ready to submit your research? Choose BMC and benefit from:

- fast, convenient online submission

- thorough peer review by experienced researchers in your field

- rapid publication on acceptance

- support for research data, including large and complex data types

- gold Open Access which fosters wider collaboration and increased citations

- maximum visibility for your research: over $100 \mathrm{M}$ website views per year

At BMC, research is always in progress.

Learn more biomedcentral.com/submissions 